\title{
The Concept of Originality in Academic Research of Engineering
}

\author{
Muhammad Shaheen (D) \\ Faculty of Engineering \& Information Technology, Foundation University Islamabad, Islamabad, Pakistan \\ Correspondence should be addressed to Muhammad Shaheen; shaheentanoli@gmail.com
}

Received 26 August 2021; Revised 13 October 2021; Accepted 24 November 2021; Published 11 December 2021

Academic Editor: Enrique Palou

Copyright (C) 2021 Muhammad Shaheen. This is an open access article distributed under the Creative Commons Attribution License, which permits unrestricted use, distribution, and reproduction in any medium, provided the original work is properly cited.

\begin{abstract}
The definition of research appears to be a controversial subject in the academic community. It is almost becoming apparent that research remains a key element in master's and doctoral degrees. Originality is, to varying degrees, the primary concern for the genuineness of research, but there is a difference of opinion on the concept of originality. In practice, a subjective analysis of originality is performed at the time of the assessment of the said degrees' theses; therefore, the resulting evaluation is affected by the difference of opinion on the concept of originality. It has also emerged that the concept of originality in research is also marginally unique in various areas. This study is focused upon reaching a point of agreement for the definition of originality in the theses/dissertation of masters and doctorate degrees in engineering only. The outcome of the research should be something new and originally contribute to the body of knowledge. This study focused on to arrive at an accurate definition of originality in university degrees in the field of engineering. An online survey was designed and carried out on the basis of evidence and expert opinion. The survey was distributed amongst engineering peers. The results of the survey are systematically summed up in the study.
\end{abstract}

\section{Introduction}

The assessment of MS (Masters in Science) and PhD (Doctorate of Philosophy) thesis/dissertation in engineering is carried out in three different ways. (1) The thesis is evaluated in relation to the originality of the subject in the field of application. (2) Evaluation is based on an original contribution of the content to the body of knowledge. (3) $\mathrm{PhD}$ theses are generally evaluated according to the originality of the contribution made to the theoretical body of knowledge [1-3]. The thesis/dissertation is a requisite for graduate students (the students of masters or $\mathrm{PhD}$ degree) to complete their degrees, and original research should essentially be the part of it. Creation of new knowledge, proposing a new approach, an extension of existing work, finding solutions for new or present problems, and proclaiming results are known as original research, but a summary, survey, review, or fusion on the domain area or existing research cannot be considered as original research [4-6]. It is agreed that the contribution of research to the body of knowledge is essential, but what are the conditions to ordain the contribution as original is not a binary issue (a problem with two states "true/false" or "yes/no") and yet a mystical one [7-9].

The problem of defining originality of research is becoming very important in academic communities [10-13]. In the academic sector, originality is highly regarded as a critical decision factor for project grants, standing appointments, funding, and scholarships [14]. Such evaluations can compromise somewhat the quality of originality because written proposals for grants/projects are based on industrial problems and seek only solutions to this specific problem, which may or may not inspire a contribution to the body of knowledge. The evaluation of the academic thesis/ dissertation remains a unique state of affairs. A thesis/dissertation especially in an engineering discipline, at times, instigates a research question solved without retaining a clear concept of its application in the industrial problems, for example, proposing the use of Manhattan distance instead of Euclidean distance in $\mathrm{K}$ means clustering may not be traced back to industrial problems. These research problems, however, when solved, add a considerable value to existing 
solutions to industrial problems. The thesis/dissertation is evaluated largely by peers [15] [See 16, 17].

In English, originality is something new, unique, and uncommon. Besides the above basis for classifying research studies, there is another basis for differentiation in research studies that is academic and industrial research. The difference in academic and industrial research is also well realized by Vedovello [18], and Table 1 provides the differences as identified by Vedovello. The academic A very comprehensive argument-based study is conducted by Nissan [19], a long time ago in which a difference in these two kinds of research is identified based on the experience of the author. Nissan experienced pure or basic research problems mostly addressed in academic settings and applied problems in industrial settings, most of the time, but this should not be always true. Nissan further argued that academic research is unique in its peer review, character, and contribution to the body of knowledge. Industrial research, on the other hand, is primarily conducted to attain the goals of its parent organization. Most of the time, the peer review of the resulting product is conducted by the customer or a layman resulting in profitability rather than novelty. It could be considered specific and dignified if academic research would take the assignment of extending the theoretical foundations of a field, where the uniqueness of the applications of such theoretical foundations can be taken into account in industrial research. Besides the basic classification, research can also be classified as academic and industrial research. Esham [20] pointed out the differences between academic and industrial research in a table (Table 1).

Academic research also differs from industrial research based on its purposes. Extending the theory of the field can be defined as academic research. Prideaux of Charles Darwin University (https://www.cdu.edu.au/sites/default/ files/Bridging\%20the\%20Gap\%20Between $\% 20$ Academic $\% 20$ Research\%20and\%20Industry.pdf) in a PowerPoint presentation listed the differences between academic and industrial research. Academic research does not have any overarching agenda, while industrial researchers work on a very specific agenda. It includes the contribution to the body of knowledge (BoK), the generalization of the contribution, and the creation of relations between the new work and the body of existing knowledge. In contrast, the application of this theory to unique contexts or solutions of an industry may be placed under industrial research. The word "industry" here is used in its broadest sense, obscuring everything where a theory proposed in the BoK is applied. Industrial research is needsbased, and its objectives are to resolve specific industrial problems without considering the contribution to the theoretical foundations of the concept. Some industrial research is generic, but even that can only be generalized to the scope of that particular industry. Another question that may arise after this description is to which end the differentiation in academic and industrial research is needed? This differentiation becomes important only when assessment comes in. If the assessment of particular research is not in question, such differentiation may reduce productivity and may constrain the creativity of an individual. In academic settings, when research is assessed for award of a degree or promotion in a tenure, the question of originality and the quality of originality comes into play. This differentiation is productive and essential in such scenarios [See 21-23].

Another issue which may arise is, why the author approached the field of engineering only. It comes to an understanding that the nature of the research question addressed in different domains is different. The research problem of an engineering field appears to be remarkably similar to an industrial research problem due to the nature of the engineering field. The body of engineering knowledge contains to a large extent the design and development of structures, its maintenance protocols, and the quality mechanisms associated with these structures. Problems in industrial research are also essentially based on similar notions. It becomes a step more difficult to differentiate between the concept of originality in academic and industrial engineering research problems, for which some specific questions to address this concern are added to the list of questions proposed in this study [See 24].

This study will examine the concept of originality in engineering for the thesis/dissertation of $\mathrm{MS} / \mathrm{PhD}$. The issues covered in this document include

(1) What is the concept of originality in academic research in $\mathrm{MS}$ and $\mathrm{PhD}$ in computer science and engineering?

(2) How to conceptualize or describe originality in engineering?

Why it is important to identify originality. Producing something original in research is critical to the survival of the field because if the original things are not brought, the body of knowledge will stop and the realm will die. In $\mathrm{MS} / \mathrm{PhD}$, originality is essential because the industrial counterpart is specific in combating industrial problems without paying specific attention to the contribution to body of knowledge. Put differently, if the problem from the industry is assessed, it may not essentially virtualize a contribution to the body of knowledge, but for an academic degree, we need to ensure such contribution. Since there is no precise definition of originality for $\mathrm{MS} / \mathrm{PhD}$ thesis; therefore, quality of research is unmeasurable, and the concept of originality varies in all domains including engineering, arts and humanities, social sciences, business, and management.

To answer these questions, an online questionnaire was designed and sent to researchers/experts ( $\mathrm{PhD}$ graduates) from all over the world. The questions for the questionnaire are designed based on existing definitions of research and originality in the literature and the factors which could be inferred from the extant literature. Different definitions available in the literature are summarized to attain the absolute concept of originality for master's and doctoral engineering students.

The study is organized as follows. Section 2 describes the extant literature on originality. The problem statement is defined formally in Section 3, In Section 4, a detailed methodology to reach a generic definition of research originality in $\mathrm{MS} / \mathrm{PhD}$ dissertation is given. The conclusion is presented in Section 5 . 
TABLE 1: Difference between academic and industrial research (source: [18]).

\begin{tabular}{lcc}
\hline Typical aspects & University & Industry \\
\hline Focus of the R\&D & Basic research: curiosity-oriented & Applied research; experience oriented \\
Basic rationale & Advance knowledge & Increase efficiency \\
Aim & New ideas & Profits \\
Characteristics & Idea-centered & Practical, product-centered \\
Framework & Open & Close, confidential \\
Evaluation & By peers & By the boss \\
Schedule & Open ended & Tight, predetermined \\
Recognition & Scientific honor & Salary increases \\
\hline
\end{tabular}

\section{Literature Review}

The originality of the research for many reasons is being thoroughly debated. From a linguistic perspective, the word originality is defined as the capacity to think independently and creatively (Oxford dictionary) and also, "the quality of being special and interesting and not the same as anything or anyone else" [25]. According to philosophy, "original refers to the source or earliest state of a person or thing" [26]. Originality in research means that the work represents the author's perspective in which the author had outlined arguments from the literature to support his arguments. The study of Gillian Clarke and Ingrid Lunt shed some light on the thin line between "originality" and "publishability." Clarke defines that the word originality in research is almost equal to the publishable work [7]. Polanyi and Michael in 1962 defined originality of discovery as the degree of its unexpectedness [2]. In the essay, originality is attributed to the creation of knowledge. There are multiple definitions of originality available in the literature $[7,13]$, but coming to a generic definition of research, originality is the main concern in academic communities. The endless discussion about the concept of originality now gives the impression that the generic definition of originality will not be concluded due to differences of opinion that are often supported by contradictory but valid arguments from one field to another and from one peer to another. Throughout this scenario, Cryer [27] suggested reassessing originality through a three-step process to identify, interpret, and demonstrate originality. In light of the guidelines of Philipps [28], the University of Melbourne has developed criteria to assess the originality of intellectual work.

The subjective debate on the concept of originality produced multiple questions for doctoral and other postgraduate students. Before proposing a guideline-based solution to the students, it is necessary to discuss the difference in academic and nonacademic research. There are quite a few studies in this domain for which a thin line between these two concepts is vigorous to render. Esham [20] formulated the difference in university and industry research through a table (Table 1) in which the focus of university (hereinafter called academic) research is basic research, and the focus of industrial research is applied which means that the academic research aims new ideas and industrial research aims an increase in efficiency of the product or system. Brew [29] examined academic research from a curiosity perspective. Knowledge generation and where the knowledge generated is used for economic development is considered industrial research. The definition of originality in academic settings specifically for the award of degree theses is controversial perhaps because of nonbifurcation of academic and industrial research.

Another question in the definition of originality is the difference in the content of the domains. Mallard and Lamont [30] underlined the difference in concepts of originality in different fields. Contributing to the body of knowledge is not limited to discovery in these fields. The change in perspective or context for which the study is being carried out may also rationalize the need for new research. The impact of diversity in the content of domain effects on the notion of originality is discussed [13].

The concept of originality in master's and doctorate theses is regarded as subjective. Delamont et al. revealed that there are some nondeterministic assumptions by people about good work and contribution to overall knowledge $[7,31]$.

AQF said the master's degree is an application of a set of advanced knowledge in a range of contexts for research and knowledge. The doctoral specification includes the demand for a substantial body of knowledge for the research, study, and development of new knowledge [32]. Higher Education Commission of Pakistan like many other education regulatory commissions of the world defines quality assurance mechanisms for doctoral degrees which is publication and peer review [33]. Clark et al. concluded on originality as one of the essentials for a research degree and agreed with Lovitts [34] on the view that the concept of originality and contribution to the knowledge are related but different concepts.

Barlosius [13] worked on the concept of originality in natural sciences, medical science, and engineering disciplines based on research proposals submitted. Three different meanings of originality are given in three modes and conclude that there are disciplinary differences between the concepts of originality. "The modes of scientific originality correspond to extrascientific notions for which only scientific rationales of originality are insufficient." Similarly, the University of Melbourne in a report [35] showed the academic objectives of undergraduate, graduate, and doctoral students. The academic objective of the master's level is a simple originality that includes reshaping the material or reappropriation of information. The aim of a $\mathrm{PhD}$ is the creative originality that results in new knowledge. The study also sets out an originality criterion. Baptista et al. [3] worked to find a connection between originality, creativity, 
and innovation in $\mathrm{PhD}$. The study considered the diversity of areas as a challenge to reach an agreed-upon definition of originality.

Gill [36] worked on the concept of originality in doctoral research and the means to formulate independent contribution to the body of knowledge. Gill et al. considered inappropriate formulation and articulation as a major reason for not discovering the originality. Philips [28] identified few key areas for determining the originality which includes new empirical research, reinterpreting an existing material, redoing in a new region, producing evidence for an old issue, alternative methods in cross disciplines, researching unexplored areas, original synthesis, and presenting knowledge in an original way [37].

The literature review converged on a few points. A rigorous study in specific fields to solve a problem or minimize the limits by a scientific method is research, if it is original, that is the greatest condition. It is vital to research to obtain a graduate degree. The broad term "originality" is an indicator for measuring or accessing the quality of research. To standardize the thesis evaluation process, the thesis supervisor and student approach should be uniform and require a generic definition of research. Defining originality has so far been an open debate which is far from being the conclusion which has arisen as the need to find a generic definition of originality. This study aims to achieve a definition and extent of originality that should be there in the graduate and $\mathrm{PhD}$ thesis/engineering dissertation.

Originality definition: originality can be defined as, "A new and unique knowledge added to the body of knowledge of a domain and discovered through research, experiment, or observation to solve the realworld problem."

\section{Methodology}

The questionnaires are used as a research tool for the present article. These questionnaires were uploaded to an online website and sent to several universities, colleges, higher education institutions, and research organizations worldwide. Industry in every region of the world is impacted by the benefits of research. Perhaps, the originality of the defined terms is not the main concern of these research efforts. Furthermore, the industry is not very well aware of the specific terminologies and mechanisms that are used in academic research. Consequently, industrial resources are partly approached to differentiate the concept of originality in academia and industry. The online questionnaire was chosen to collect the responses because of ease of its access by a global community and universality of the problem. The concept of originality in an engineering thesis is not the concern of a single region; it is debated in universities all over the world. About the design of the questionnaire, it was designed to translate the required information into a series of short and complete questions. The questionnaire is sent to multiple indigenous scholars for its simplification and coherence. The changes suggested by these experts are made in the questionnaire. Some of the questions are unrestricted and open ended to allow respondents to share important opinions on their subject. Some questions were restricted and closed to allow the respondent to select the options from the given list. The questions (Table 2 annexed as Annex A) are prepared according to the rationales given in Table 3 (annexed as Annex B). Once the answers to the questions were received, they were shortlisted and organized to ensure that they contribute to the final objective of the research. Before having thorough deliberations on the demographics of the respondents and results obtained through the questionnaire, a discussion on the questions included in the questionnaire is given in Table 2 (Annex A).

The questionnaire (given at Annex A (Table 2)) was designed mainly to summarily extract information about some aspects of originality in masters and doctorate research. The answers provided by respondents are analyzed statistically. In order to better communicate the results, the results achieved are renovated and presented as answers to the following eight questions.

\subsection{Research Questions with Description}

Q1. What is the concept of originality in $\mathrm{MS}$ and $\mathrm{PhD}$ thesis/dissertation of engineering?

Aim: the concept of originality is a long-debated issue and the academic communities have informally classified it as an NP-hard problem for which the assessment of originality in some content is solely based upon peer review. There are many aspects of evaluation of the concept of originality. Determining originality in a research depends upon type of research (academic and industrial), domain of research (science, engineering, and social science) and the academic level on which the research is conducted (masters, $\mathrm{PhD}$ ). Keeping all in view, question 1 is framed to give a holistic definition of originality.

Q2. What is the difference (where applicable) between the concept of originality in the master's thesis and the doctoral thesis?

Aim: the research on the concept of originality has recently gained much significance, so it is appealing to discover qualitative differences in the concept of originality in MS thesis and $\mathrm{PhD}$ dissertation. Therefore, question 2 was raised.

Q3. What is the difference between the concepts of originality in academic and industrial research?

Aim: the fundamental difference between academic and industrial research is not made explicit and less emphasized in the extant literature. A definitional difference, given in the literature review section, is that academic research is adding something to the body of knowledge, and it is evaluated by means of disciplinewise academic standards. While industrial research is undertaken to find solutions to industrial problems, whether or not it contributes to the body of knowledge. This difference may not be well understood by the academic and industry communities for which the responses obtained in this research are summarized in the Results section of this question. 
TABLE 2: Questionnaire-the concept of originality (Annex A).

\begin{tabular}{|c|c|c|}
\hline $\begin{array}{l}\text { S. } \\
\text { no. }\end{array}$ & Question & Description \\
\hline 1 & $\begin{array}{l}\text { Is there a difference between research in general and research for } \\
\text { the award of MS degree? (yes/no). If yes, can you briefly state the } \\
\text { difference? }\end{array}$ & $\begin{array}{l}\text { The question was included to bifurcate research in general fro } \\
\text { academic research and whether the academic research is only } \\
\text { be undertaken at the } \mathrm{PhD} \text { level or at both masters and } \mathrm{PhD}\end{array}$ \\
\hline 2 & $\begin{array}{l}\text { Is there a difference between research in general and research for } \\
\text { the award of } \mathrm{PhD} \text { degree? (yes/no). } \\
\text { If yes, can you briefly state the difference? }\end{array}$ & $\begin{array}{l}\text { The question was included to bifurcate research in general from } \\
\text { academic research and whether the academic research is only to } \\
\text { be undertaken at the } \mathrm{PhD} \text { level or at both masters and } \mathrm{PhD} \text { ? }\end{array}$ \\
\hline 3 & $\begin{array}{l}\text { Should there be a difference in the method of evaluation of } \\
\text { research for MS (engineering) and MS/M.Phil (in other } \\
\text { disciplines)? (yes/no). If yes, can you briefly state the difference? }\end{array}$ & $\begin{array}{l}\text { This question was included to evaluate the differences in } \\
\text { definitions of originality in masters thesis across the disciplines } \\
\text { because of the difference in nature of the contents of a particular } \\
\text { discipline. }\end{array}$ \\
\hline 4 & $\begin{array}{l}\text { Should there be a difference in the method of evaluation of } \\
\text { research for PhD (engineering) and PhD (in other disciplines)? } \\
\text { (yes/no). } \\
\text { If yes, can you briefly state the difference? }\end{array}$ & $\begin{array}{c}\text { This question was included to evaluate the } \\
\text { definitions of originality in doctorate thesis acr } \\
\text { because of the difference in the nature of tl } \\
\text { particular discipline. }\end{array}$ \\
\hline 5 & $\begin{array}{l}\text { Is there a difference in the concept of originality in } \mathrm{MS} \text { and } \mathrm{PhD} \text { ? } \\
\text { (yes/no) }\end{array}$ & $\begin{array}{l}\text { This question was included } \\
\text { difference in the extent of origi }\end{array}$ \\
\hline 6 & $\begin{array}{l}\text { pace provided) } \\
\text { pace }\end{array}$ & $\begin{array}{l}\text { This question was included to find whether the difference in MS } \\
\text { and } \mathrm{PhD} \text { theses is related to the volume of work or quality. }\end{array}$ \\
\hline & $\begin{array}{l}\text { you think that the difference } \\
\text { no). }\end{array}$ & $\begin{array}{l}\text { This question was included to find whether the difference in MS } \\
\text { and } \mathrm{PhD} \text { theses is related to the volume of work or quality. }\end{array}$ \\
\hline 8 & $\begin{array}{l}\text { Are the projects without any factor of research are acceptable at } \\
\text { the MS level? (yes/no) }\end{array}$ & $\begin{array}{l}\text { The projects th } \\
\text { developed. This } \\
\text { ar }\end{array}$ \\
\hline 9 & $\begin{array}{l}\text { re the projects without any factor of research are acceptable at } \\
\text { le PhD level? (yes/no) }\end{array}$ & $\begin{array}{l}\text { The projects conclud } \\
\text { solving a social scena } \\
\text { these projects a }\end{array}$ \\
\hline 10 & $\begin{array}{l}\text { a survey considered to research at the MS level if it contributes } \\
\text { nique points of interest to the domain? }\end{array}$ & $\begin{array}{l}\text { A thorough survey concluding at unique } \mathrm{p} \\
\text { acceptable as MS thesis or }\end{array}$ \\
\hline 11 & $\begin{array}{l}\mathrm{PhD} \text { level if it contributes } \\
\text { in? }\end{array}$ & $\begin{array}{r}\text { A thorough survey co } \\
\text { acceptab }\end{array}$ \\
\hline 12 & not exist in the market & $\begin{array}{l}\text { Unique applicatic } \\
\text { use. Are th }\end{array}$ \\
\hline 13 & ? exist in the market & $\begin{array}{l}\text { Unique applications of } \\
\text { use. Are these ap }\end{array}$ \\
\hline 14 & $\begin{array}{l}\text { Should MS thesis contribute something to the body of } \\
\text { knowledge? }\end{array}$ & $\begin{array}{c}\text { Body of knowledge (BoK) of the domains is defined. Should every } \\
\text { MS thesis contribute something to extend that body of } \\
\text { knowledge? }\end{array}$ \\
\hline 15 & $\begin{array}{l}\text { Should } \mathrm{PhD} \text { thesis contribute something to the body of } \\
\text { knowledge? }\end{array}$ & $\begin{array}{c}\text { Body of knowledge (BoK) of the domains is defined. Should every } \\
\text { PhD thesis contribute something to extend that body of } \\
\text { knowledge? }\end{array}$ \\
\hline 16 & $\begin{array}{l}\text { Contribution to the body of knowledge and originality are } \\
\text { alternate terms? }\end{array}$ & $\begin{array}{c}\text { Contribution to the body of knowledge is accredited to creativity } \\
\text { and originality. Are these alternative terms or have different } \\
\text { meanings? }\end{array}$ \\
\hline 17 & If you answered "no" to Q16, what is the difference? & The difference between both the terms is to be stated \\
\hline
\end{tabular}


TABLE 2: Continued.

\begin{tabular}{l} 
S. \\
no. \\
\hline 1. Put a tick and cross against each of the following. Which of the \\
following are considered as original for MS and PhD? \\
(i) Contribution to the body of knowledge \\
(ii) A study with unique conclusions \\
(iii) An application of the theory which does not exist before \\
(iv) A method/algorithm/procedure which does not exist before \\
and can be converted to an application in future \\
(v) An attempt to develop a method/algorithm/procedure which \\
resulted in failure and warned others not to proceed in the same \\
direction again \\
(vi) An attempt to develop a method/algorithm/procedure which
\end{tabular}

18 resulted in failure and does not warn others to proceed in the same direction again

(vii) Combination of multiple existing methods of the domain in which degree is sought out had never been combined in the same way in past

(viii) Combination of multiple existing methods of a domain other than the domain in which degree is sought out had never been combined in the same way in past

(ix) An application of the method of domain A to a problem of domain $\mathrm{B}$ where the degree is claimed in domain $\mathrm{A}$

(x) An application of the method of domain A to a problem of domain $\mathrm{B}$ where the degree is claimed in domain $\mathrm{B}$

19 Is the definition of originality in research the same for MS in science and MS in engineering disciplines? (yes/no)

If you answered "no" to Q9

(i) Which of the factors given in Q18 define originality in MS 20 (science)?

(ii) Which of the factors given in Q18 define originality in MS (engineering)?

21 Is the definition of originality in research the same for a $\mathrm{PhD}$ in science and $\mathrm{ahD}$ in engineering disciplines? (yes/no)

If you answered “no” to Q21

22 (science)?

(ii) Which of the factors given in $\mathrm{Q} 18$ define originality in $\mathrm{PhD}$ (engineering)

2. Which of the following is/are true?

(i) A research study extracted from a part of MS thesis and published in a quality journal is sufficient for determining the originality of research work?

(i) A research study that is a true representative of one's whole MS thesis published in a quality journal is sufficient for determining

23 the originality of research work?

(ii) A research study extracted from a part of MS thesis and presented in a reputed conference is sufficient for determining the originality of research work?

(iii) A research study that is a true representative of one's whole MS thesis published in a reputed conference is sufficient for determining the originality of research work?
In this question, multiple concepts that exist in one form or another are given in the options list. The respondents are asked to pick one or many as more precisely defining the concept of originality in $\mathrm{MS}$ and $\mathrm{PhD}$

Science and engineering are two different domains and both have some specific requirements for undertaking research. Is the definition of originality in MS research of both is the same or different?

The options list provided in Q18 covered most of the existing definitions or concepts of originality. Which one of them is valid for MS engineering?

Science and engineering are two different domains and both have some specific requirements for undertaking research. Is the definition of originality in $\mathrm{PhD}$ research of both is same or different?

The options list provided in Q18 covered most of the existing definitions or concepts of originality. Which one of them is valid for $\mathrm{PhD}$ engineering?

This question is included to find the relationship between publishability and originality in MS thesis. The question is also meant to determine the quality sources for publication of original content. 
TABle 2: Continued.

\begin{tabular}{l} 
S. \\
no. \\
\hline 3. Which of the following is/are true? \\
(i) A research study extracted from a part of a PhD thesis and \\
published in a reputed journal is sufficient for determining the \\
originality of research work? \\
(ii) A research study that is a true representative of one's whole \\
PhD thesis published in a reputed journal is sufficient for \\
determining the originality of research work? \\
(iii) A research study extracted from a part of the PhD thesis and meant to determine the quality sources for publication of original \\
presented in a reputed conference is sufficient for determining the \\
originality of research work? \\
(iv) A research study that is a true representative of one's whole \\
PhD thesis published in a reputed conference is sufficient for \\
determining the originality of research work? \\
Any other comments
\end{tabular}

TABle 3: : Rationale of the questions added in the questionnaire given in Table 3 (Annex B).

Question no. (in Table 3)

Q1 and 2

Q3, 4, 19, 20, 21, 22, 23, and 24

Q5, 6, 7, 8, 9, 18, 23, and 24

Q10, 11, 12, 13, 18, 19, 20, 21, 22, 23 , and 24

Q14, 15, 16, 17, 18, 19, 20, 21, 22, 23 , and 24
Rationale

The difference between the research conducted in the academics and industry is worked by $[18,29]$ (cuhk.edu.hk/clear/rs/research_in_institutions.pdf) and cited in the literature review section. The questions are included to have peer's input on its practical recognition.

The study conducted by Mallard and Lamont [30] (cited in the literature review) considered research of a few domains different from others. Barlosius [13] worked on the concept of originality in natural/ medical sciences and engineering disciplines only and emphasized the difference in the concepts of the research in different domains. The questions are included to have peer's input on its practical recognition.

Australian Qualification Framework (AQF) and Higher Education Commission Pakistan (HEC) specified the qualification of masters's degree research to be an application of an advanced body of knowledge in a range of contexts for research and scholarship. The specification of the doctoral degree includes applying a substantial body of knowledge to research, investigate, and develop new knowledge $[32,33]$

The definitions and concepts of originality as presented by different researchers in many studies referred in the literature review $[3,7,13,25,34]$ among others emerged the needs of classifying different forms of existing research studies including but not limited to surveys, applications of a theory/concept from body of knowledge, critical reviews, and many more into one of the nonresearch, academic research, and industrial research classes.

The definition of originality in thesis/dissertation is concluded above after thorough review of multiple definitions and concepts of originality given in the literature. Contribution to the body of knowledge as a requisite for research is almost agreed among the researchers. These questions are framed to identify such contributions in the existing types of problems which are researched.
Q4. What is the difference between the concept of originality in engineering thesis/dissertation and other disciplines thesis/dissertation?

Aim: engineering is a field in which the research problems are precisely deterministic and have a rigorous objective, and their results are evaluated against measurable metrics. Some studies are examined in the literature review section which categorizes research from different fields into different groups. This question will help assess differences in definitions of originality in the engineering thesis/dissertation and other disciplines.

Q5. What is the difference between originality and creativity in $\mathrm{MS} / \mathrm{PhD}$ thesis/dissertation?
Aim: research is "creative and systematic work started to increase the stock of knowledge" [38]. Given that the contribution to the body of knowledge is also known for creativity and originality, "are they the same?" is important to understand.

Q6. What is the difference between the concept of originality in science thesis/dissertation and engineering thesis/dissertation?

Aim: the definition and scope of science and engineering are different. The originality of the $\mathrm{PhD}$ thesis/ dissertation is defined as the contribution to the body of knowledge. This definition is global and feeds some questions such as, is the body of knowledge of science and engineering on a theoretical level the same? If that 
is the case, how is a contribution going to be differentiated? This question will be used to evaluate differences in definitions of originality in science and engineering.

Q7. Is originality essential for $\mathrm{MS}$ thesis and $\mathrm{PhD}$ dissertation or both?

Aim: in general practice, the MS thesis generally encompasses an analytical approach and originality encompasses reworking the material and/or examining existing information in another way. While, doctoral studies take a speculative approach. This question aims to assess the significance of the originality of MS and $\mathrm{PhD}$ in different regions of the world.

Q8. Is originality justified in the development of applications, projects, and investigations in the light of certain existing knowledge?

Aim: the concept of "originality" and the level of originality of the work in thesis/dissertation are of concern to many students. Does an engineering application, design project, or survey merit a contribution to the knowledge base? The results obtained from the responses to the question will be beneficial to consider the said studies as original.

Responses from respondents are presented in the next section.

\section{Results}

The questionnaire designed for the study was sent to 1,813 respondents who belong to different countries around the world. 638 submissions were received. Demographic characteristics of recipients and respondents are given in Table 4. Most of the respondents are from academic faculty. Least number of responses are received from industrial sector shown as other HEI in Table 4 . A total of $92 \%$ of the respondents were doctorate degree holders and was expected because they are in a much better position to respond to these questions.

The responses received can be categorized into the following four categories.

(1) QWUR (questions well understood and responded): questions that are well understood and adequately answered by the respondents

(2) QNUR (questions not understood and responded): the questions are well responded, but the answers given were not relevant to the questions.

(3) QNR (questions not responded): questions that are not answered at all.

(4) QHR (questions half responded): questions where the Boolean part (yes/no, true/false) of the question is only answered and the subjective part is ignored.

Table 5 provides the number of responses classified in the above categories. From the data given in Table 5, we can see that most of the questions added in the questionnaire are well understood and responded. This was because of the valuable inputs of the experts who helped to rephrase and reorganize the questions to make them clear and understandable.

The questions given in the questionnaire are divided in two major parts. (1) The questions on which a binary response was expected from the respondents. (2) The questions in which multiple choices are given to respond and they are descriptive in nature as well. The graph representation of different dimensions of the results will increase the length of this script for which two representative plots are shown in Figures 1-3. Figure 1 shows the percent division of responses received on binary questions. Three questions $(\mathrm{Q} 18,23,24)$ played decisive role in the eight research questions for which their responses are shown in Figures 2 and 3. In response to Q18 (Annex A (Table 2)), most of the respondents considered a study as original if it concludes with unique findings or discovers some new algorithm/ methods. A complete breakdown of the responses is shown in Figure 2.

In Figure 3, the responses on the relation between publishability and originality are plotted. The responses are plotted separately for masters and $\mathrm{PhD}$ theses. Most of the respondents acknowledged the dependence of publishability on originality if the publication is directly extracted from the central theme of the thesis.

The questions in the final section are examined in light of the responses received from respondents. Each of the questions reviewed is attached to the corresponding questions on the questionnaire. Q1 is answered at the end.

The order in which the questions were presented is changed in the following paragraph:

4.1. Q2. What Is the Difference (If Any) between the Concept of Originality in MS Thesis and PhD Dissertation? (Related Questions: 5, 6, 7, 14, 15, 18). The binary response of about $75 \%$ of respondents was "yes," of which $72 \%$ voted for the fact that the difference lies in the amount of work. Originality is regarded as essential for the master's thesis and the doctoral thesis with a condition imposed by a few respondents that the originality of the MS thesis is essential if it is supplemented by research. The respondents were of the view that the contribution to the body of knowledge is essentially invaluable when the word "research" is encountered. However, the scope of the contribution can vary in both instances. For MS degree, any scientific amendment/improvement/extension established through a known scientific process to any of the existing model/algorithm/processes is considered to be a contribution to the body of knowledge without going into the details of granularity and complexity of the contribution. Doctoral thesis in terms of the nature of originality will be similar to that of masters, but the granularity and complexity of the problem addressed in doctoral theses should be greater. For $\mathrm{PhD}$ thesis, a granular and complex scientific amendment/ improvement/extension established through a known scientific process to any of the existing model/algorithm/process is considered to be a contribution to the body of knowledge of engineering. Some respondents responded using examples. Two-three of these are copied. 
TABLE 4: Demographics of recipients and respondents.

\begin{tabular}{lccc}
\hline S. no. & Category & Recipients & Respondents \\
\hline 1 & Academic faculty & 1360 & 513 \\
2 & Administrative staff of HEIs & 240 & 71 \\
3 & Research organizations & 109 & 43 \\
4 & Other HEI & 104 & 11 \\
5 & Percentage of PhD's & $85 \%$ & $92 \%$ \\
6 & Total & 1813 & 638 \\
\hline
\end{tabular}

TABLE 5: Number of responses into QWUR, QNUR, QNR, and QHR.

\begin{tabular}{lcccc}
\hline Q. no. & QWUR & QNUR & QNR & QHR \\
\hline 1 & 499 & 55 & 12 & 72 \\
2 & 504 & 48 & 9 & 77 \\
3 & 520 & 72 & 13 & 33 \\
4 & 542 & 48 & 9 & 0 \\
5 & 602 & 25 & 11 & 62 \\
6 & 532 & 32 & 12 & 81 \\
7 & 522 & 16 & 19 & 0 \\
8 & 580 & 26 & 32 & 0 \\
9 & 577 & 29 & 32 & 0 \\
10 & 603 & 21 & 17 & 0 \\
11 & 609 & 14 & 15 & 0 \\
12 & 613 & 12 & 13 & 0 \\
13 & 618 & 14 & 6 & 0 \\
14 & 602 & 4 & 27 & 0 \\
15 & 580 & 48 & 10 & 0 \\
16 & 550 & 25 & 41 & 0 \\
17 & 580 & 6 & 33 & 0 \\
18 & 601 & 19 & 19 & 0 \\
19 & 601 & 38 & 27 & 27 \\
20 & 550 & 30 & 11 & 0 \\
21 & 597 & 11 & 30 & 0 \\
23 & 572 & 9 & 25 & 0 \\
24 & 602 & 299 & 108 & 17 \\
25 & 603 & 38 & 24 & 0 \\
Average & 231 & & & 0 \\
\hline
\end{tabular}

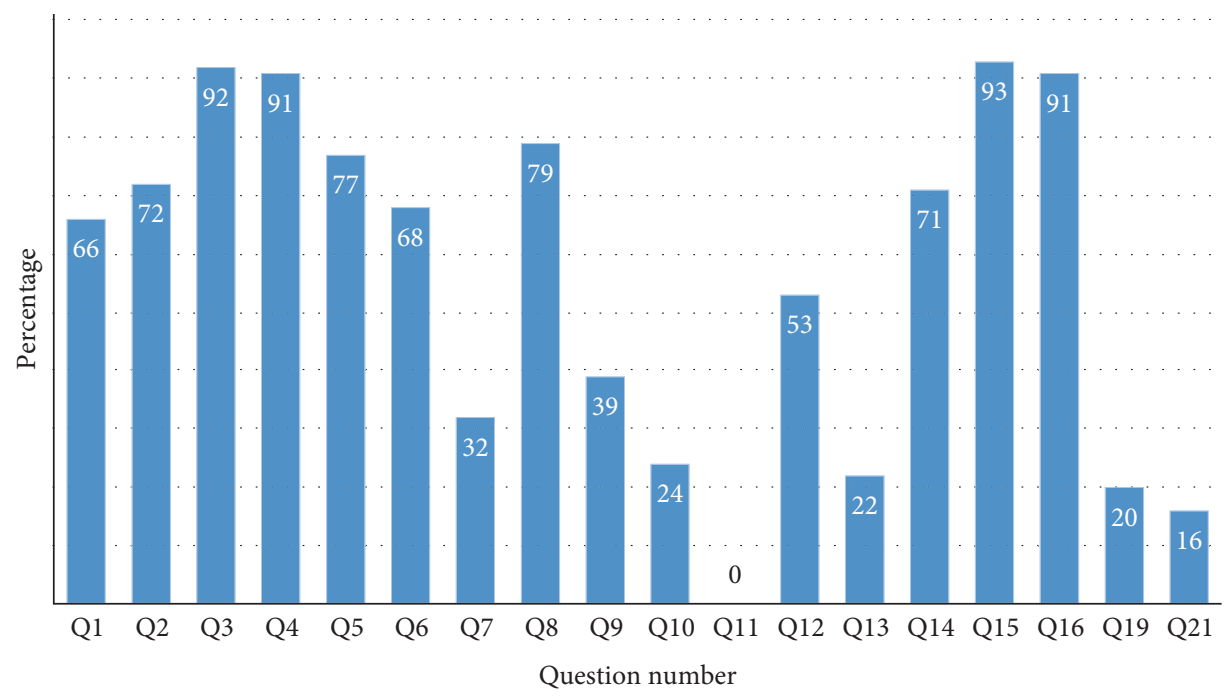

Figure 1: Percent of "yes" responses on binary questions of questionnaire given in Table 2 (Annex A). 


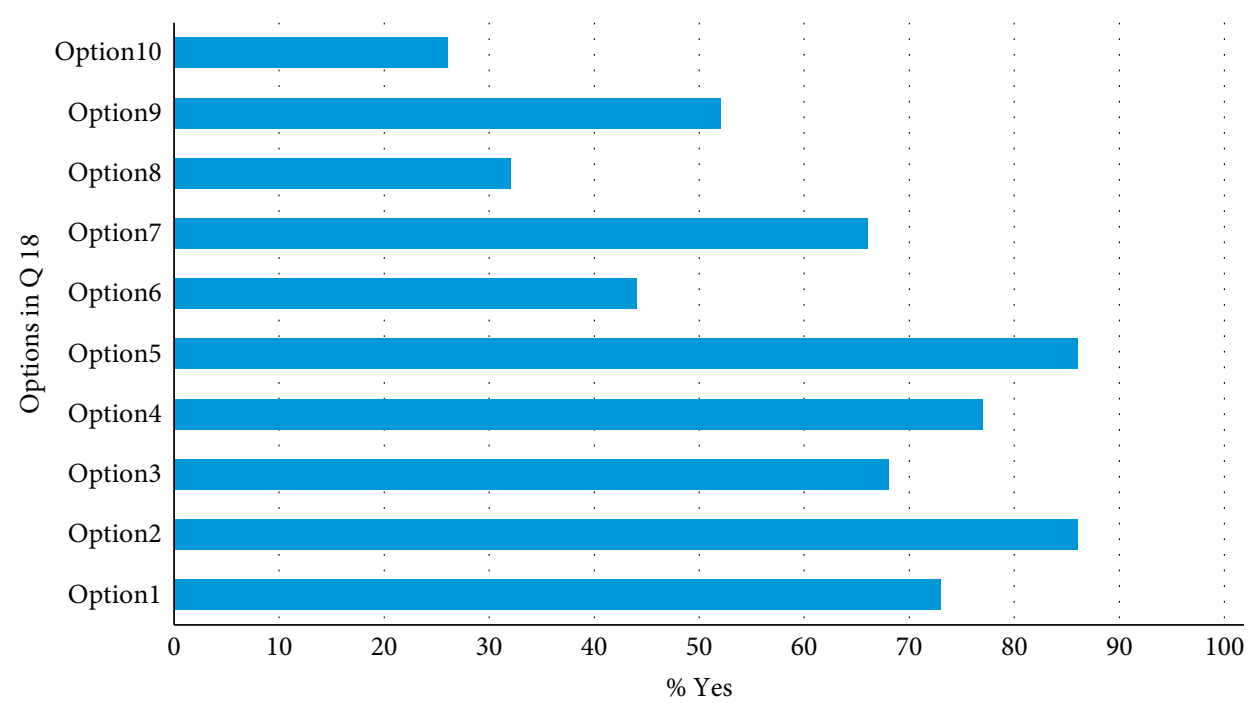

Figure 2: Percent of responses on different options given for question no. 18 of questionnaire (Annex A (Table 2)). Option 1: contribution to the body of knowledge. Option 2: a study with unique conclusions. Option 3: an application of the theory which does not exist before. Option 4: a method/algorithm/procedure which does not exist before and can be converted to an application in future. Option 5: an attempt to develop a method/algorithm/procedure which resulted in failure and warned others not to proceed in the same direction again. Option 6: an attempt to develop a method/algorithm/procedure which resulted in failure and does not warn others to proceed in the same direction again. Option7: combination of multiple existing methods of the domain in which degree is seeked out which had never been combined in the same way in past. Option 8: combination of multiple existing methods of a domain other than the domain in which degree is seeked out which had never been combined in the same way in past. Option 9: an application of the method of domain A to a problem of domain B where the degree is claimed in domain A. An application of the method of domain A to a problem of domain B where the degree is claimed in domain B.

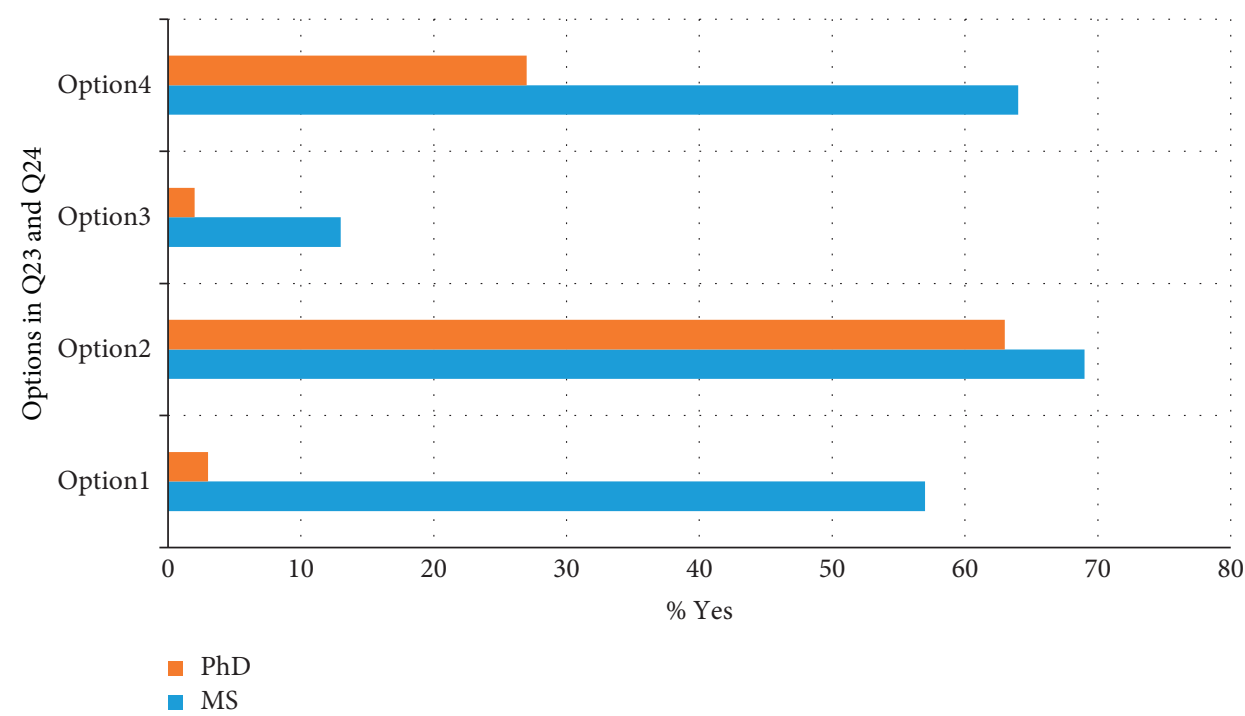

Figure 3: Percent of responses on the relationship between originality and publishability in response to question nos. 23 and 24 of the questionnaire given in Table 2 (Annex A). Option1: a research study extracted from a part of the thesis and published in a reputed journal is sufficient for determining the originality of research work? Option 2: a research study which is a true representative of one's whole thesis published in a reputed journal is sufficient for determining the originality of research work? Option 3: a research study extracted from a part of the thesis and presented in a reputed conference is sufficient for determining the originality of research work? Option 4: a research study which is a true representative of one's whole thesis published in a reputed conference is sufficient for determining the originality of research work?

"600-level courses in the domain of computer science include the course of the operating system. An extension proposed in the existing set of scheduling algorithms, even a single line added to the pseudocode of, for example, FCFS, may result in a meagre improvement in the execution time of the algorithm when hypothesized, experiment, and tested, 
and results are compared with the existing scheduling algorithm and be considered as an original contribution to the body of knowledge of computer science $>$ operating systems."

"As per my understanding, a compact current operator proposed for stack algorithms is novel and merited to contribute something primitive to the body of knowledge."

"For example, a mechanism which constrained the germination of pesticides in a specific area for some geographical factors needs a new proposal in the body of knowledge to address the same."

\subsection{Q3. What Is the Distinction between the Notion of} Originality in Academic and Industrial Research? (Related Questions: 1, 2, 8, 9, 10, 11, 12, 13). A unique response received on the question was that the concept was not very much cited in the literature but seem interesting and may aid the process of defining originality at two different levels, i.e., academic and industrial. 68\% of respondents considered academic and industrial research to be different concepts. The differences noted in academic and industrial research are primarily related to the difference between originality and creativity. Most of the responses received were supporting the work of Runco and Eisenman [39] according to which originality is a necessary part of creativity, but creative things are more than just original. They also solve a problem or more generally are appropriate one way or the other. Academic research mainly contributes to the body of knowledge without taking into account the conversion of this one into a product. Industrial research, however, focuses on the market and revenues for which intellectual esteem and commitment to the body of knowledge can be compromised. This bifurcation of the concept of originality in academic and industrial research needs further study to identify the outcomes of different groups of students with and without a clear and concise concept of this difference. A few excerpts from the interviewees are presented.

"To discover the relationship in mass and force is academic research, machining a vehicle on this principle may be industrial."

"Fibonacci series is the outcome of academic research. An example of industrial research may be to file a patent on discovering a pin for placement in Coca-Cola tins."

"The terms of academic and commercial are more appropriate for differentiating both in the true sense. The primary objective of academic research is to devise a component for body of knowledge which had not been done before. These components are integrated or fashioned/integrated into multiple ways to meet different commercial ventures."

4.3. Q4. What Is the Difference between the Concept of Originality in Engineering Thesis/Dissertation and Other Disciplines Thesis/Dissertation? (Related Questions: 3, 4)

(1) An approximate consensus is reflected in the reply that the concept of originality in today's world depends on the discipline/field. The differences are derived from the responses of the respondents listed in the following:

(i) The original content of engineering research is more quantifiable than elsewhere

(ii) In engineering disciplines, improvement in performance and efficiency is linked to the concept of originality in which some respondents did not accept as valid

(iii) The original content is relatively easier to identify in engineering dissertations than other disciplines. The open nature of a domain makes accurate identification and definition of originality difficult.

(2) As stated earlier, in engineering disciplines, any scientific change/improvement/extension established by a known scientific process to one of the existing models/algorithms/process is considered to contribute to the body of knowledge. In contrast, relationships between variables not previously worked are considered original. This means that the type of work ("Relationship between variables") to be done is defined for most theses. While original engineering work has, for the most part, fewer clues begin with.

(3) Reproduction of research in a different setting is valid in most disciplines [40], which is not the case in engineering.

4.4. Q5. What Is the Difference between Originality and Creativity in MS/PhD Thesis/Dissertation?(Related Questions: $8,9,10,11,12,13,18)$. The way the question is conceived in this study could not be acknowledged by most respondents. $61 \%$ of the respondents did not find a relevant question in the questionnaire to answer it. On average, $31 \%$ of respondents judged this question to be out of scope and context. A few respondents assumed that the design difference was already indicated in response to question 3. The responses from a few respondents and the author's point of view are that originality and creativity are two different concepts, but they are usually alternated. Creativity is a potential of the mind to conceive and expound original and innovative ideas, but every innovative idea is not essentially researchable. An extremely good and unique application of a theory is a work of ultimate worth and may inspire the creative strength, but is not original. $81 \%$ of respondents did not accept an application as an original contribution, but the value and usefulness of an application sometimes make it ambiguous. In the thesis/dissertation of MS and $\mathrm{PhD}$, this confusion may lead to the endorsement of a research abstract based on an unoriginal but creative question. What if the application is regarded to get a creative result and the theory as original? Although the generalizability of this statement is not clear, the fact lies somewhere near this concept. 
4.5. Q6. What Is the Difference between the Concept of Originality in Science Thesis/Dissertation and Engineering Thesis/Dissertation? (Related Questions: 19, 20, 21, 22). $82 \%$ of respondents replied "no," saying that the concept of originality is no different in science and engineering. The differences given by some respondents are not only different from each other but also belong to different fields. However, some respondents' unique responses are reworded to facilitate understanding and are copied.

"Science and engineering are different in the nature of content for which the concept of originality differs in them. In science, a theory without its expected novelty in the application domain is original. In engineering, originality is established when the concept establishes its worth in the theory as well as application."

"In science, the concept is original only when it is established through a scientific process, while in engineering, a concept is certified when it is tested against an existing concept and show some improvement in any of the testing aspect established through benchmarks."

"A theory is original in science when it is not proposed in the literature before but it may or may not be original when its worth in the application cannot be established."

"Science demands originality in the philosophy of the content and engineering demands the same in content."

The difference in the concept of originality in science and engineering is not well established through the responses. However, a few insights may become light for the theses of science and engineering. The body of knowledge of science contains the phenomena related to the physical and natural world and is related to the philosophy of the processes involved in different terrestrial and natural phenomena. A contribution to this philosophy may be considered as original in science. It will be seen as original and generalizable. Engineering, on the other hand, is concerned with the application of the knowledge to solve the problems associated with the industry/society for which the condition of generalization may be compromised in its thesis/dissertation. A major limitation in identifying originality in the content of engineering thesis is the similarity of the engineering research problem with the engineering problem associated with industry. The definition of originality concluded in this study entitles an engineering problem as original when it adds something to the defined, scoped, and delimited body of knowledge of the engineering domain. The development of an algorithm, for example, justifies a unique appendix in an engineering field, but a single computer program extracted from an existing algorithm cannot.

4.6. Q7. Is Originality Essential for MS Thesis and PhD Dissertation or Both? (Related Questions: 8, 9, 10, 11, 12, 13, 14, 15, 18). $73 \%$ of respondents responded "yes" to this question. The remainder responded "no" for MS only. Neither respondent disagreed that the content of the doctoral thesis should be original. The definition of originality is provided to be different in a few responses, but whatever definition is, it is agreed upon that originality is a must for $\mathrm{PhD}$ dissertation and agreed with a little exception for MS thesis.
4.7. Q8. Is Originality Warranted in the Development of Application, Project, and Survey Based on Some Existing Knowledge? (Related Questions: 8, 9, 10, 11, 12, 13, 18). $78 \%, 61 \%$, and $94 \%$ of respondents voted against the consideration of an application, a project, and a survey, respectively, as an original for a doctorate in engineering. $47 \%$, $21 \%$, and $76 \%$ of respondents voted against application, project, and survey, respectively, as valid research for MS thesis in engineering. A few respondents questioned the validity of the too broad word "project" in its context and cannot be covered by a binary question. The responses can be summarized in the following insights.

(i) Any project which is developed without contributing a new algorithm/technology or technique to the body of knowledge may not be considered as a valid thesis at both MS and PhD levels

(ii) An application built from scratch and based on an existing theoretical concept that has never been materialized before may also be considered original

(iii) Survey-based studies, even with unique and novel results, may not qualify the originality test at any level

\section{Conclusion and Future Work}

5.1. Q1. What Is the Concept of Originality in MS and PhD Theses of Engineering? (Related Questions: All Questions). The concept of originality in the master's and doctoral theses of engineering disciplines is related to the contribution of the thesis to the body of knowledge of that particular field. The master's and doctoral theses differ by the granularity and complexity of the concept. $\mathrm{PhD}$ thesis contributes specifically to the philosophical area of the whole knowledge, and MS should better contribute to a concept based on philosophy. The level of different programs leading to a degree in engineering if they are classified according to the undergraduate project, the master's thesis, and the doctoral thesis can generate a hierarchy. The undergraduate project can end at the application level by designing a usable application of the philosophy proposed at the PhD level and algorithmized at the master's level. Research at MS and $\mathrm{PhD}$ levels should be publishable, but the publication is not enough to prove the originality of the work. Unique applications of the original work are published in a number of journals and lecture papers. In the same way, studies with unique conclusions are also publishable. Another aspect of originality that we do not work enough on is the difference between academic research and nonacademic research. Academic research is mentioned to expand the body of knowledge of a field. Many applications of this extension can be developed in nonacademic research. Academic research can result in an intellectual contribution and nonacademic research to a unique industrial application.

A unique application of a method from one domain to another domain may not be considered as a contribution. For example, a data mining algorithm developed in the big data domain if applied to the agricultural dataset, where this has not been done before and does not justify any 
contribution to the body of knowledge in any field. However, an existing data mining algorithm that requires an extension for direct application to agricultural datasets will represent a contribution after extending it to meet new requirements. An in-depth review of an area followed by a scientific research process can sometimes lead to questioning the validity of the hypotheses and illuminate other theses of not following the track and can also be considered original.

Generalization can also inform the validity of the original content. Any conclusion reached after a thorough scientific process is original if it can be generalized to a certain point. The extent of generalizability may circumscribe the scope of originality. Another issue related to the originality of the thesis frequently asked in academic circles is related to the field in which the contribution is made. A thesis of the domain $\mathrm{A}$ is with a unique contribution to the knowledge of domain $B$, should it be accredited for the domain $\mathrm{A}$ or $\mathrm{B}$ ? We have to work to define the issue from an educational point of view. Despite all the discussions, peer evaluation of the originality of the work remains inevitable.

The work can be extended in future to produce a general definition of originality in MS and PhD theses. The type of differences in the various aspects of the domains will be developed to conclude the same. The concept of academic and nonacademic research may be developed in the future using datasets from academia and industry.

\section{Appendix}

\section{Data Availability}

The numeric data used to support the findings of this study are summarized and included within the article.

\section{Conflicts of Interest}

The author declares that there are no conflicts of interest.

\section{Supplementary Materials}

Annex A: questionnaire-the concept of originality. Annex $B$ : rationale of the questions added in the questionnaire given in Table 3. (Supplementary Materials)

\section{References}

[1] M. Presthus, "How to frame your contribution to knowledge? A guide for junior researchers in information systems," NokoBit, vol. 24, no. 1, 2016.

[2] UKEssays, "PhD proposal writing contributing to knowledge," 2018, https://www.ukessays.com/essays/education/anoriginal-contribution-to-knowledge-education-essay.php? vref $=1$.

[3] F. Baptista, R. Holley, and A. Tesch, "The doctorate as an original contribution to knowledge: considering relationship between originality, creativity and innovation," Frontline Learning Research, vol. 3, no. 3, pp. 51-63, 2015.

[4] OECD, "Frascati manual 2015: guidelines for collecting and reporting data on research and experimental development,"
The Measurement of Scientific, Technological and Innovation Activities, OECD Publishing, Paris, France, 2015.

[5] Bently, Sherman, Gangjee, and Johnson, Intellectual Property Law, Oxford University Press, Oxford, UK, 5th edition, 2018.

[6] Rozakis, Schaum's Quick Guide to Writing Great Research Papers, Mc-graw hill Publishers, New York, NY, USA, 2nd edition, 2007.

[7] G. Clarke, "The concept of 'originality' in the Ph.D.: how is it interpreted by examiners?" Assessment \& Evaluation in Higher Education, vol. 39, no. 7, pp. 803-820, 2014.

[8] Denicolo, "Assessing the Ph.D.: a constructive view of criteria," Quality Assurance in Education, vol. 11, no. 2, pp. 84-91, 2003.

[9] J. Tinkler, The Doctoral Examination Process, Open University Press, " Maidenhead, UK, 2004.

[10] K. Bakiogulo, "Quality criteria of research perceived by academics in social sciences at higher education," US-China Education Review A, vol. 6, no. 3, pp. 1-13, 2009.

[11] J. Foster and E. Rzhetsky, "Tradition and innovation in scientists' research strategies," American Sociological Review, vol. 80, no. 5, pp. 875-908, 2015.

[12] Z. Toprak and V. Yücel, "A peculiar practice of academic writing: epidemic writing in the Turkish graduate education," Cogent Education, vol. 7, no. 1, Article ID 1774098, 2020.

[13] Barlosius, "Concept of originality in the natural science, medical, and engineering disciplines: an analysis of research proposals," Science, Technology \& Human Values, vol. 44, no. 6, pp. 915-937, 2018.

[14] W. Shibayama, "Measuring originality in science," Scientometrics, vol. 122, no. 1, pp. 409-427, 2020.

[15] H. Lehan and Mika, "Reviewing the review:An assessment of dissertation reviewer feedback quality," Journal of University Teaching and Learning Practice, vol. 13, no. 1, p. 4, 2016.

[16] H. Bourke, "Examining Ph.D. And research masters theses," Assessment \& Evaluation in Higher Education, vol. 38, no. 4, pp. 407-416, 2013.

[17] K. Mullins, "It's a Ph.D., not a Nobel Prize': how experienced examiners assess research theses," Studies in Higher Education, vol. 27, no. 4, pp. 369-386, 2002.

[18] Vedovello, "Firms' R\&D activity and intensity and the university-enterprise partnerships," Technological Forecasting and Social Change, vol. 58, pp. 215-226, 1998.

[19] Nissan, "Similarities and differences between industrial and academic research," Research Management, vol. 9, no. 4, pp. 211-219, 1966.

[20] Esham, Strategies to Develop University-Industry Linkages in Sri Lanka, National Education Commission Sri Lanka, Colombo, Sri Lanka, 2008.

[21] H. Batty, "Contributing to knowledge in creative writing," Text: Journal of writing and writing courses, vol. 44, pp. 1-16, 2017.

[22] Wicker, The Good Supervisor: Supervising Postgraduate and Undergraduate Research for Doctoral Theses and Dissertations, Palgrave Macmillan, Basingstoke, UK, 2nd edition, 2012.

[23] G. Winter and Green, "The 'academic' qualities of practice: what are the criteria for a practice based Ph.D," Studies in Higher Education, vol. 25, no. 1, pp. 25-37, 2000.

[24] M. Polanyi, "The republic of science: its political and economic theory," Minerva, vol. 38, no. 1, pp. 1-32, 2000.

[25] AHD (American Heritage Dictionaries), American Heritage Dictionary of the English Language, Houghton Mifflin Harcourt, Boston, MA, USA, 5th edition, 2015. 
[26] M. Maccalman, T. Russel, and H. Fullagar, An Oxford Companion to the Romantic Age: British Culture, Oxford University Press, Oxford, UK, 2009.

[27] Cryer, The Research Student's Guide to Success, Open University Press, Maidenhead, UK, 1st edition, 2006.

[28] P. Philipps, How to Get a Ph.D.., Open University Press, 4th edition, 2005.

[29] L. Brew, Academic Research and Researchers, Open University Press, Berkshire, UK, 2009.

[30] G. Mallard and G. Lamont, "Fairness as appropriateness: negotiating epistemological differences in peer review," Science, Technology \& Human Values, vol. 34, no. 5, pp. 573-606, 2009.

[31] A. Delamont and Parry, Supervising the Doctorate: A Guide to Success, Open University Press, Maidenhead, UK, 2nd edition, 2004.

[32] AQFC (Australian Qualifications Framework Council), Australian Qualifications Framework, AQFC, Canberra, Australian, 2013, http://www.aqf.edu.au/, 2nd edition.

[33] HEC (Higher Education Commission) Pakistan, Minimum Criteria for MS/M.Phil and Ph.D. Programs, https://hec.gov. pk/english/scholarshipsgrants/Documents/MPHIL_Ph.D._ Criteria.pdf, 2020.

[34] Lovitts, Making the Implicit Explicit: Creating Performance Expectations for the Dissertation, Stylus, Sterling, VA, USA, 2007.

[35] TUM (The University of Melbourne), Developing originality, Ver 10-12, https://services.unimelb.edu.au/_data/assets/pdf_ file/0009/471267/Developing_originality_Update_051112. pdf, 2020.

[36] D. Gill, "Originality and the Ph.D.: what is it and how can it be demonstrated?" Nurse Researcher, vol. 22, no. 6, pp. 11-15, 2015.

[37] Edwards, "What does originality in research mean? A student's perspective," Nurse Researcher, vol. 21, no. 6, pp. 8-11, 2014.

[38] F. Manual, The Measurement of Scientific, Technological and Innovation Activities-Guidelines for Collecting and Reporting Data on Research and Experimental Development, Organization for Economic Co-operation and Development (OECD), OECD Publishing, Paris, France, 2015.

[39] I. Runco and Eisenman, "Creativity, originality and appropriateness: what do explicit instructions tell us about their relationships," Journal of Creative Behavior, vol. 39, no. 2, pp. 137-148, 2005.

[40] P. Phillips, "How to get a Ph.D," .: A Handbook for Students and Their Supervisors, Open University Press, Maidenhead, UK, 5th edition, 2010. 